\title{
PARALYSIS OF OCULAR MUSCLES FOLLOWING SPINAL ANAESTHESIA
}

\author{
BY \\ MAJOR J. Biggam, R.A.M.C. \\ BANGALORE, INDIA
}

AT a large military hospital in England, between January and July, 1927, I examined five cases of paralysis of one or other of the recti muscles of the eye following on the use of stovaine as a spinal anaesthetic.

Although stovaine has been extensively used as a spinal anaesthetic in this hospital since 1915 there is no record of any case of paralysis of ocular muscles following its use, with the exception of these five cases which occurred early in 1927.

Until this date the stovaine used was obtained from one firm, and, after the occurrence of the cases, analysis of the supply by this firm revealed nothing deleterious.

Since July, 1927, the stovaine has been obtained from another firm and up to July, 1931, no further ocular complications have arisen.

No important alteration in the method of administration or in the dosage employed has been made during the 16 years under review.

The following are short notes of the individual cases :-

\section{Corporal G.S., aged 22 years, Disease-Chronic Appendicitis}

January 29, 1927. Operation-Appendicectomy.

January 31, 1927. Vomiting and jaundice.

February 3, 1927. Headache. (There is no note of when this started.)

February 10, 1927. Complaints of diplopia only on looking to the left.

February 14, 1927. I saw the patient for the first time. He had a slight but definite paresis of the left external rectus muscle. He had single vision when looking straight ahead. The pupils were equal in size and normal in reactions.

February 20, 1927. On re-examining the patient I found no trace of muscle paresis nor could diplopia be elicited by any test. The Maddox rod showed no distant muscle balance error. Complete examination showed no eye abnormality except one dioptre of myopic astigmatism in each eye.

I lost touch with this case from February 20, 1927 until May 31, 1927, when I heard from a doctor in Leeds that " $\mathrm{He}$ is attending me now for very intractable headache and he still has some weakness of the eye muscles with diplopia if he tries to look to the extreme left." As far as I know he had not been examined again by an oculist.

Unfortunately I heard no more of this case.

\section{Driver H.M., aged 2I years, Disease-Subluxation Internal Semilunar Cartilage}

March 5, 1927. Operation-Excision of internal semilunar cartilage 10.30 a.m.

March 6, 1927. Intense headache, frontal, occipital, and down the back of the neck started at 2 a.m.

March 11, 1927. Headache continued. At 3 p.m. he woke from sleep with double vision. Examination showed a marked paralysis of the left external rectus. He had single vision only on looking to the extreme right. 


\section{PARALYSIS OF OCULAR MUSCles}

March 15, 1927. He still had slight continuous frontal headache. The diplopia was unchanged.

March 23, 1927. Diplopia only on movements of the eyeballs to the left of the middle line.

March 28, 1927. Diplopia only on movements of the eyeballs to the extreme left.

March 30, 1927. Double vision completely gone. Complete examination revealed no other abnormality. Patient stated that his headache continued, although gradually diminishing in intensity, till March 27, 1927, and then almost abruptly disappeared.

July 4, 1927. The patient, who had been discharged from the Army in the meanwhile, was traced into a non-medical government institution the medical officer of which reported "no return of double vision since his reception here on June 3, 1927."

\section{Sergeant S.A.S., aged 30 years, Disease-Chronic Appendicitis}

April 12, 1927. Operation Appendicectomy-Anaesthetic stovaine, supplemented by a partial general anaesthetic.

April 14, 1927. Headache started. He also complained of stiffness in the back of the neck and sleeplessness.

April 15, 1927. He first noticed the diplopia. Examination revealed a marked degree of paralysis of the left external rectus. Except for the paralysis of this muscle no other eye abnormality external or internal was found. He still complained of "dragging pains" in the back of the neck.

April 21, 1927. Diplopia unaltered. Headache still persisted.

April 25, 1927. Headache had disappeared. Muscle paralysis improving slightly.

April 28, 1927. Diplopia only on looking to the left of the middle line.

May 5, 1927. He felt fit, but there was no change in the muscle condition since April 28, 1927.

May 15, 1927. Condition unchanged. Complete examination revealed no defect other than that of the left external rectus muscle. He was discharged from Hospital and given leave of absence.

May 23, 1927. According to a letter from the patient, the diplopia is improving.

June 24, 1927. He stated in his letter that the diplopia has now entirely disappeared, the end point of the disappearance of the double vision coming rather suddenly and unexpectedly.

\section{Driver G.W., aged 22 years, Disease-Acute Appendicitis}

May 11, 1927. Operation-Appendicectomy.

May 13, 1927. Some frontal headache since operation but no eye trouble until this morning when he noticed diplopia. Examination revealed slight but definite paresis right external rectus muscle.

May 21, 1927. From the 13th until this date severe headache was a marked feature of the case. The muscle paresis and diplopia remained unaltered.

May 31, 1927. The headache gradually lessened in intensity and the muscle paresis improved.

June 4, 1927. He felt fit. Headache had disappeared. He did not now complain of diplopia, which however could still be readily elicited with red and green glasses when he looked to the right.

June 10, 1927. He had no symptoms. Doubtful diplopia could be elicited with special tests on extreme eye movements to the right. He was discharged Hospital for leave.

\section{Corporal A.R.C., aged 28 years, Disease-Subacute Appendicitis}

July 1, 1927. Operation-Appendicectomy.

July 2, 1927. Severe headache which continued for a week gradually diminishing in intensity.

July 9, 1927. He noticed diplopia on wakening. Examination revealed marked left external rectus paralysis. He had single vision only when looking to the extreme right. Little change was noticed for 3 weeks and then gradual improvement began. 
August 9, 1927. Could now see single when looking straight ahead. He stifl had diplopia on movements of the eyeballs to the left of the middle line.

August 18, 1927. He did not complain of diplopia which however could easily be elicited with special tests when he looked to the left.

August 28, 1927. Very slight diplopia still remained.

September 18, 1927. Complete disappearance of diplopia. Nothing abnormal noticed on complete examination of each eye. The patient had no headache and felt fit.

\begin{tabular}{c|c|c|c|c|c}
\hline CASE. & G.S:* & H.M. & S.A.S. & G.W. & A.R.C. \\
\hline $\begin{array}{l}\text { Number of days elapsing be- } \\
\text { tween operation and onset } \\
\text { of paralysis - }\end{array}$ & & & & & \\
$\begin{array}{l}\text { Number of days elapsing be- } \\
\text { tween onset and disappear- } \\
\text { ance of paralysis - - }\end{array}$ & 10 & 19 & 3 & 2 & 8 \\
\hline Eye affected - - - - & L & L & L & R & L \\
\hline
\end{tabular}

* Note. - The figures given for the case of G.S. are probably unreliable. He was not under my observation at the time of the onset of the muscle paresis, and he was lost sight of six days later. The other cases were under my observation from the beginning, and were observed, or traced, until the condition had completely cleared up.

\section{Summary}

1. The occurrence, under the conditions mentioned, of an isolated group of five cases within six months suggests some toxic element in the drug in use during this period.

2. All cases complained of headache, usually very severe, which preceded the onset of muscle paralysis by one to seven days. The headache lasted from one to three weeks.

3. The paralyses were maximal at their onset, remained stationary for varying periods, and then gradually improved. In the case of G.S. complete recovery appears to have been followed by relapse, about which, however, no accurate information is available.

4. In one case the paralysis occurred not more than two days after the administration of the drug.

5. In no case was any abnormality, other than that of the muscle affected, discovered. 